\title{
Mercado, políticas públicas y cooperativas de productores en la lechería uruguaya a comienzos del siglo XX
}

Market, public policies and producer cooperatives in the Uruguayan dairy at the beginning 20th century

Mercado, políticas públicas cooperativas de produtores no laticínio uruguaio no início século 20

\section{Juan Pablo Martí ${ }^{1}$}

Recibido: 12 de abril de 2019

Aceptado: 30 de noviembre de 2019

Publicado: 31 de enero de 2020

Cómo citar este artículo: Martí, J. P. (2020). Mercado, políticas públicas y cooperativas de productores en la lechería uruguaya a comienzos del siglo XX. Cooperativismo \& Desarrollo, 27(116)1-33. doi: https://doi.org/10.16925/2382-4220.2020.01.02

1 Artículo de Investigación doi: https://doi.org/10.16925/2382-4220.2020.01.02

1 Profesor de Historia, Diplomado en Economía, Magister en Historia Económica, Candidato a doctor en Ciencias Sociales

Profesor en Régimen de Dedicación Total de la Facultad de Ciencias Sociales, Universidad de la República, Uruguay

Correo electrónico: juanpablo.marti@cienciassociales.edu.uy

Orcid: https://orcid.org/0000-0002-4162-1773 


\title{
Resumen
}

En las primeras décadas del siglo XX se comenzó a desarrollar la producción lechera en Uruguay. Si bien los antecedentes remiten a los tiempos de la colonia, es solo a partir de las técnicas de refrigeración que la producción lechera se expandió y aumentó decididamente el número de productores. Para el desarrollo de la lechería en Uruguay fueron fundamentales las cooperativas de productores. La primera de ellas fue la Cooperativas de Lecherías Sociedad Anónima (COLE S.A.) que luego dio lugar a Conaprole, la cual se convirtió en líder del sector y en el presente es la primera empresa exportadora uruguaya. La creación de COLE S.A. se dio a instancia de los productores lecheros. En cambio, para la creación de Conaprole se conjugaron la movilización de los productores lecheros y las políticas públicas. Conaprole es un caso particular de cooperativa creada por la Ley 9526 de 1935. Esta ley, además de otorgarle el monopolio en la industrialización y comercialización de leche en la ciudad de Montevideo, estableció una serie de medidas de intervención estatal. Esta investigación se pregunta por las razones del surgimiento de Conaprole. Analiza el contexto de la época en sus aspectos económicos y sociales, fundamentalmente atendiendo a la participación de los productores lecheros y sus organizaciones. También estudia el contexto político, analizando las políticas públicas y las ideas que estaban detrás de la creación de cooperativas y la evolución del marco normativo que desembocó en la creación de Conaprole. Finalmente, se muestra cómo la creación de Conaprole sintetiza un proceso que se nutre de la movilización de los productores y de la acción de los poderes públicos.

Palabras claves: industria lechera, cooperativas, COLE, Conaprole, políticas públicas.

L78 Estudios de la industria: productos primarios y construcción: política gubernamental

Q13 Mercados Agrícolas y Comercialización; Cooperativas; Agronegocios

P13 Empresas cooperativas

\begin{abstract}
In the first decades of the twentieth century, milk production began to develop in Uruguay. Although the antecedents refer to colonial times, it is only due to refrigeration techniques that milk production expanded and the number of producers decidedly increased. Producers cooperatives were essential for the development of dairy in Uruguay. The first of these was the Cooperativas de Lecherías Sociedad Anónima (COLE S.A.) which later gave rise to Conaprole, which became the industry leader and is currently the first Uruguayan exporting company. The creation of COLE S.A. came into being at the behest of dairy producers. On the other hand, for the creation of Conaprole the mobilization of dairy producers and public policies were combined. Conaprole is a particular case of a cooperative created by Law 9526 of 1935. This law, in addition to granting it a monopoly on the industrialization and commercialization of milk in the city of Montevideo, established a series of state intervention measures. This research probes into the reasons for the emergence of Conaprole. It analyzes the context of the time in its economic and social aspects, fundamentally noting the participation of dairy producers and their organizations. It also studies the political context, analyzing public policies and the ideas that were behind the creation of cooperatives and the evolution of the regulatory framework that led to the creation of Conaprole. Finally, it shows how the creation of Conaprole summarizes a process that draws on the mobilization of producers and the action of public authorities.
\end{abstract}

Keywords: dairy industry, cooperatives, COLE, Conaprole, public policies. L78 Industry studies: primary products and construction: government policy ÇQ13 Agricultural Markets and Marketing; Cooperatives; Agribusiness P13 Cooperative companies 


\section{Resumo}

Nas primeiras décadas do século XX, a produção de leite começou a se desenvolver no Uruguai. Embora os antecedentes se refiram aos tempos coloniais, é apenas devido às técnicas de refrigeração que a produção de leite se expandiu e o número de produtores aumentou decididamente. As cooperativas de produtores foram essenciais para o desenvolvimento de laticínios no Uruguai. A primeira delas foi a Cooperativas de Lecherías Sociedad Anónima (COLE S.A.), que mais tarde deu origem à Conaprole, que se tornou líder do setor e atualmente é a primeira empresa exportadora uruguaia. A criação da COLE S.A. surgiu a pedido dos produtores de leite. Por outro lado, para a criação do Conaprole foram combinadas mobilização dos produtores de leite e políticas públicas. Conaprole é um caso particular de uma cooperativa criada pela Lei 9526 de 1935. Essa lei, além de lhe garantir o monopólio da industrialização e comercialização do leite na cidade de Montevidéu, estabeleceu uma série de medidas de intervenção estatal. Esta pesquisa investiga as razões do surgimento de Conaprole. Analisa o contexto da época em seus aspectos econômicos e sociais, observando fundamentalmente a participação dos produtores de leite e de suas organizações. Também estuda o contexto político, analisando políticas públicas e as idéias que estavam por trás da criação de cooperativas e a evolução do marco regulatório que levou à criação do Conaprole. Por fim, mostra como a criação do Conaprole resume um processo que se baseia na mobilização de produtores e na ação de autoridades públicas.

Palavras-chave: indústria de laticínios, cooperativas, COLE, Conaprole, políticas públicas.

L78 Estudos da indústria: produtos primários e construção: política do governo

Q13 Mercados e Marketing Agrícolas; Cooperativas; Agronegócio

P13 Empresas cooperativas

\section{Introducción}

El trabajo forma parte de una línea de investigación que busca elaborar una historia del cooperativismo en el Uruguay reconstruyendo el proceso histórico de las diferentes modalidades cooperativas. En particular, se estudia el vínculo existente entre los matrices de surgimiento y las modalidades de desarrollo de las cooperativas. Para ello se indaga en los orígenes y los condicionantes de su surgimiento y la estructura que adoptan las diferentes modalidades cooperativas.

Se exploran los orígenes de las cooperativas lecheras en Uruguay para la industrialización y comercialización de la leche en Montevideo. Tradicionalmente la importancia de las cooperativas en el sector lechero es muy fuerte. En América Latina la producción láctea es uno de los sectores donde hay mayor presencia cooperativa. Las cooperativas procesan entre el $20 \%$ y $25 \%$ de la leche producida en Latinoamérica y son responsables del 40 \% de la exportación de productos lácteos. Dentro de este grupo de cooperativas exportadoras se encuentran, entre otras: SanCor de Argentina, COLUN de Chile y Dos Pinos de Costa Rica (FAO-FEPALE, 2012, p. 40). Es interesante reflexionar respecto a por qué existe esta tendencia a cooperar y asociarse entre los productores lecheros. Esto se debe a condicionamientos estructurales y también a características del proceso histórico del surgimiento de la lechería. Respecto de 
los condicionamientos estructurales, la concentración de cooperativas en el sector lácteo podría explicarse porque los productores tienen buenos motivos por los cuáles les conviene cooperar. En particular, la cooperación en la industria láctea presenta especiales relaciones técnicas de producción. La industrialización de la producción láctea, requiere de condiciones de producción que escapan y superan la etapa primaria de producción lechera y obligan a su procesamiento. A su vez, es en el proceso de industrialización que se agrega valor a un bien bastante homogéneo y esto permite la valorización del trabajo de los productores².

En lo que refiere al proceso histórico de surgimiento y desarrollo del cooperativismo en el sector lechero en Uruguay se evidencia una original situación. Las cooperativas de productores estuvieron presentes desde temprano en la industrialización y comercialización de la leche en Montevideo a través de Cooperativas de Lechería S. A. Posteriormente, se creó la Cooperativa Nacional de Productores de Leche (Conaprole). Se trata de un caso particular de cooperativa creada por la Ley 9526 de 1935 (Martí, 2013). Esta ley, además de otorgarle el monopolio en la industrialización y comercialización de leche en la ciudad de Montevideo, estableció una serie de medidas de intervención estatal (Martí, 2014). El caso de Conaprole es particularmente interesante en términos de su creación puesto que, además de ser la única creada por ley, es la cooperativa más grande del Uruguay, la mayor empresa láctea y la principal empresa exportadora del país durante largos períodos. Al igual que en el resto de América Latina, en Uruguay la industria láctea es liderada por una empresa cooperativa (Uruguay_XXI, 2019a): en el año 2012 Conaprole captó el 65 \% de la leche remitida a la industria (INALE, 2012, p. 11). De acuerdo a datos estimados en base al último censo cooperativo de $2008^{3}$, Conaprole pesaba entre el 35 \% y 40 \% del Valor Bruto de Producción (VBP) de las

2 Al momento de analizar los motivos por los cuales puede ser conveniente asociarse y cooperar, Bisang et al. (2005) señalan los siguientes: a) las ganancias colectivas emergentes de condiciones territoriales; b) las necesidades de coordinación derivadas de las relaciones técnicas de producción; c) la necesidad de coordinación temporal de inversiones o en la provisión de la cadena insumo/producto; d) la necesidad de coordinación estratégica relacionada con las funciones de producción de actividades específicas por requerimientos de escalas mínimas, riesgos de inversión, desarrollo de externalidades o bienes club; y e) las ganancias emergentes de relaciones de cooperación que facilitan los procesos de aprendizaje que aprovechan de la sinergia y la posibilidad de aprendizajes de elementos tácitos.

3 El II Censo Nacional de Cooperativas y Sociedades de Fomento Rural (2008-2009) de Uruguay fue organizado por la Comisión Honoraria del Cooperativismo $(\mathrm{CHC})$ de la Oficina de Planeamiento y Presupuesto (OPP), la Confederación Uruguaya de Entidades Cooperativas (Cudecoop) y la Organización de las Naciones Unidas para el Desarrollo Industrial (ONUDI). EI Censo tomó como universo todas las entidades con naturaleza jurídica cooperativa y todas las sociedades de fomento rural activas, es decir, con actividad económica y/o social al momento de realizar el estudio (INE, 2010). 
cooperativas (Torrelli, 2012). Además en 2011 Conaprole fue la principal empresa exportadora (Uruguay-XXI, 2012, p. 7) con un $5 \%$ del total de las exportaciones uruguayas (Uruguay_XXI, 2019b).

Este trabajo se pregunta por el surgimiento de las cooperativas lecheras. Las condiciones de surgimiento delas cooperativas han sidoanalizadas por diversosautores. Charles Gide proponía clasificar a las cooperativas de acuerdo a sus "fuentes" tomando en cuenta quienes habían creado las iniciativas (Vuotto, 2003). Identificaba como las tres principales fuentes al Estado y los municipios, los patrones y los propios obreros. También mencionaba a las iglesias y la filantropía laica y "sin duda, en el futuro, los consumidores" (Gide, 1912). Más adelante Vanek (1985) reconocía cinco modalidades de nacimiento de las empresas cooperativas: la quiebra, la reorganización amigable o muy amigable, la reorganización agresiva, la formación espontánea y la formación inducida del exterior. Con algunas diferencias, y analizando el caso de Uruguay, Terra (1986) proponía distinguir las siguientes matrices de surgimiento de las cooperativas: nacidas por la transferencia a los trabajadores de empresas deficitarias; surgidas a partir del impulso autónomo de los propios socios y la organización cooperativa creada por una organización externa. Vinculado con la propuesta de Terra y atendiendo el papel que ha jugado el Estado en América Latina, en un trabajo anterior (Camilletti et al., 2005) se propuso otra matriz de surgimiento de las cooperativas: las cooperativas promovidas desde el Estado. En este mismo sentido, Neffa (1986) proponía analizar el surgimiento de las experiencias autogestionarias "desde arriba" y "desde abajo". Estudiar los factores intervinientes para la creación de las cooperativas "desde arriba", significa enfocarse en las acciones de promoción, fomento y apoyo estatal y "desde abajo" requiere considerar la acción y movilización de otros actores sociales y políticos. Desde la perspectiva de Neffa (1986) el nacimiento desde abajo responde a la lógica de la sociedad civil organizada aunque pueden estar ligadas a políticas públicas y el nacimiento desde arriba responde a la lógica de las política públicas, por más que se ejecuten en conjunto con organizaciones de la sociedad civil'4.

4 Coincidentemente con esto, pero referido a la implementación de las políticas públicas y no al surgimiento de las cooperativas se han desarrollado las visiones desde arriba y desde abajo. Esto ha dado lugar a una visión "top-down" que se centra en el análisis de las decisiones políticas de las autoridades para la implementación de las políticas públicas (Sabatier y Mazmanian, 1979). Por el contrario, la visión "bottom-up", analiza la implementación de las políticas públicas a partir del sistema de actores para evaluar la participación y los niveles de conflicto (Hjern y Hull, 1982). Como síntesis de estas dos visiones el mismo Sabatier (1986) realiza una crítica de ambas visiones -con sus fortalezas y debilidades- y propone que para comprender las políticas en las sociedades industriales modernas es más útil tomar como unidad de análisis el subsistema de políticas. Este enfoque de lo que llama "advocacy coalition framework" lo desarrolla con más detalle en trabajos posteriores (Sabatier, 1988, 1998). 
Es por ello que se tendrá en cuenta para el análisis tanto a las políticas públicas como a las acciones desarrolladas por los distintos actores sociales.

En general se entiende como política pública "un programa de acción gubernamental en un sector de la sociedad o en un espacio geográfico" (Meny y Thoenig, 1992, p. 90). En este mismo sentido, otros autores entienden a las políticas públicas como cualquier acción realizada desde el Estado, a través de sus instituciones (Varas, 1997), para influir sobre un problema que en determinado momento los ciudadanos o el propio gobierno consideran una prioridad (Tamayo Saenz, 1997, p. 281). Una definición más precisa es la propuesta Subirats et al. (2008, p. 36) quienes la conciben como: "una serie de decisiones o de acciones, intencionalmente coherentes, tomadas por diferentes actores, públicos y a veces no públicos -cuyos recursos, nexos institucionales e intereses varían- a fin de resolver de manera puntual un problema políticamente definido como colectivo".

A su vez, estos mismo autores (Subirats et al., 2008, p. 49) entienden como actor tanto a un individuo como varios individuos o una persona jurídica o un grupo social siempre y cuando "se presente y actúe con homogeneidad interna respecto a los valores e intereses que defiende y los objetivos que persigue" ${ }^{5}$. Los actores se pueden clasificar en función de su carácter público, es decir los que tienen el estatuto de actores político-administrativos o para estatales Meny y Thoenig (1992, p. 189)6. Los actores privados participan también en la constitución y estructuración del espacio de una política pública sea como destinatarios, beneficiarios o grupos de afectados - positiva o negativamente- de la política pública (Subirats et al., 2008, p. 54). Las autoridades político-administrativas -actores públicos-, los grupos-objetivo y los beneficiarios finales - actores privados- constituyen el triángulo de base de la política pública.

En función de lo anterior, se analiza el contexto de la época en sus aspectos económicos y sociales, fundamentalmente atendiendo a las acciones y movilizaciones de los productores lecheros y sus organizaciones. También se estudia el contexto político, analizando las políticas públicas y las ideas que estaban detrás de la creación de cooperativas y la evolución del marco normativo que desembocó en la creación de Conaprole.

El diseño metodológico empleado responde a la intención de ser descriptivos y explicativos a la vez. Descriptivo para dar cuenta de la trayectoria de las acciones y organizaciones de productores y las políticas públicas para la creación de las

5 Para Olson (1978) la existencia de un grupo presupone un interés común.

6 Los actores paraestatales serían aquellos actores privados en los que el Estado delega una parte de sus prerrogativas (Subirats et al., 2008, p. 60). 
cooperativas. Explicativo por buscar entender y explicar las relaciones entre la trayectoria de las acciones de las organizaciones de productores lecheros y las políticas públicas que confluyeron en la creación de la cooperativa.

En cuanto a las técnicas de recolección de información se recurrió a análisis documental, revisión de prensa de la época y entrevistas en profundidad a informantes calificados. El análisis documental se entiende como el conjunto de procedimientos destinados a captar, segmentar y representar el significado de los documentos con el objetivo de su recuperación total o parcial. Esta técnica está basada en la exploración de datos encontrados en documentos, principalmente de los archivos de las empresas, la revisión de regulaciones estatales y la información secundaria disponible. Para el análisis de la prensa se procedió a una revisión exhaustiva de la prensa de Montevideo de la época que diera cuenta de los fenómenos estudiados.

Respecto de los testimonios, se realizaron entrevistas semiestructuradas a informantes calificados, es decir, aquellas personas cuya experiencia es representativa del grupo o hecho objeto de estudio (Folguera, 1994) y que, más allá de la no representatividad estadística de los testimonios, es necesario que los mismos tipifiquen procesos históricos (Barela, Miguez, y García Conde, 2000). A efectos de la selección concreta de los entrevistados, y en la medida que no se buscaba la significación estadística sino la representación tipológica socioestructural se tomaron en cuenta las posibilidades de medios y tiempo, lo que deriva en los criterios de muestreo cualitativo propuestos por Valles (2002) de heterogeneidad y economía. Esto es lo que se conoce habitualmente como muestreo intencional: la selección de los entrevistados de acuerdo a ciertos criterios relevantes (Piovani, 2007). Evidentemente que la selección de entrevistados estuvo condicionada por la antigüedad de los fenómenos a estudiar y la posibilidad de acceder a ellos. Al tratarse de un caso antiguo se realizaron entrevistas semiestructuradas a los descendientes de los protagonistas para conocer cómo eran significados algunos temas desde la tradición oral familiar y contrastar los testimonios con la información de los documentos y las visiones de la prensa de la época. Se procuró la confiabilidad y validez a partir de la utilización de métodos combinados, lo que implicó una estrategia de triangulación de diferentes fuentes: análisis documental, revisión de prensa y testimonios. Estos últimos no solo permitieron contrastar y comprobar información, también brindaron la posibilidad de utilizar fragmentos de las entrevistas para dar solidez a la narrativa histórica

Además de esta sección, el trabajo se compone de otras tres secciones y las conclusiones. En la primera se da cuenta de la realidad de la industria lechera a comienzos del siglo XX. En la segunda se describen los esfuerzos realizados de parte de los productores y por los poderes públicos para organizar la producción 
y comercialización de leche. En la tercera se muestra cómo la confluencia de la movilización de los productores y las políticas públicas da como resultado la creación de Conaprole. Finalmente, a manera de conclusión, se recapitulan y destacan los principales hallazgos de la investigación.

\section{Industria lechera: calidad de la leche y salud pública}

\section{La industria lechera en la Edad de Piedra}

¿Quién es capaz de negar que la industria lechera está entre nosotros todavía en la edad de piedra y que solo espera el impulso vigoroso de un brazo fuerte y de una cabeza criteriosa para transformarse en una inagotable fuente de prosperidad para que vengan dotados de esas condiciones?

Maeso, 1910

A comienzos del siglo XX no existía una verdadera industria lechera en Uruguay. Eran escasos los establecimientos lecheros y se debía recurrir a la importación de manteca de la Argentina. A esto se sumaba el comportamiento fuertemente estacional de la producción ya que las vacas no recibían alimentación suplementaria: "... durante el invierno o épocas de seca, cuando los pastos naturales escasean, se nota una gran merma en la producción de leche" (Maeso, 1910). La falta de leche impedía que se instalase una industria ya que no se contaba con la materia prima suficiente. En lo referido al ganado, y a pesar de la gran cantidad de ganado vacuno con que contaba el país por esos años, las razas lecheras eran escasas y no se realizaba selección ni mestizaje. Las pocas vacas en ordeñe apenas producían un promedio de tres litros de leche diaria.

Los informes de la época reclamaban la mejora de los establecimientos llamados tambos ${ }^{7}$ con la introducción de variedades de ganado lechero, la siembra de forrajes, el ordeñe racional y planificado, entre otros aspectos. Un informe de la Comisión de Fomento de la Cámara de Diputados que acompañaba un proyecto de ley para el fomento de la lechería se expresaba en este sentido:

7 Tambo (del quechua tampu) es un término utilizado habitualmente en Argentina y Uruguay para designar a los establecimientos ganaderos destinados al ordeño de vacas y a la venta, generalmente al por mayor, de su leche. 
La República, país esencialmente ganadero, hasta el momento actual no ha obtenido más que una parte, seguramente no la más considerable, de lo que puede producir la ganadería sabía y científicamente explotada. Una de las riquezas más importantes, la leche, por los múltiples productos que de ella se obtienen, se ha descuidado de tal suerte, que puede afirmarse que varios millones de pesos se pierden cada año debido a la falta de trabajoy previsión. [...] Si a pesar de la indiferencia general pueden prosperar algunos industriales emprendedores, ¿qué sucedería si la población del país se diera cuenta de que deja escapar una de sus grandes riquezas, si se abandonaran los procedimientos de fabricación antigua reñidos con los elementales preceptos de la higiene y se explotara científicamente una parte por lo menos de la leche que produce nuestra campaña? No es dudosa la respuesta: surgiría una poderosa industria llamada a sorprender por sus resultados pecuniarios (Informe de la Comisión de Fomento de la Cámara de Diputado citado por Maeso, 1910, sp).

En el caso de Montevideo, la leche que se consumía provenía de tambos ubicados en la ciudad o sus cercanías. A medida que se desarrolló el ferrocarril, la cuenca lechera de Montevideo se expandió en un radio de $100 \mathrm{~km}$ alrededor de la ciudad. Para 1913 el 65 \% de la leche consumida por Montevideo tenía su origen en tambos rurales. En ese año, y de acuerdo a un censo lechero realizado por el Departamento de Policía Sanitaria Animal dependiente del Ministerio de Industria, existían 1930 establecimientos de lechería con un total de 180000 vacas lecheras (Ernesto Bauzá (Inspector de Policía Sanitaria Animal), citado por Bertino y Tajam, 2000).

Estos tambos presentaban diversos problemas. Unos años después esta situación es relatada por el Censo Agropecuario de 1937 ).

Los altos arrendamientos, exceso de mano de obra, falta de pastoreo suficiente o mala calidad del mismo representan también factores que unidos a los precitados [mala calidad del ganado, no producción de forraje y falta de rentabilidad del capital invertido], constituyen las caudas que determinan, en la generalidad de los casos, el fracaso de las explotaciones lecheras, (citado por Jacob, 1981, p. 220) 
En consecuencia, los productores se enfrentaban a una demanda concentrada, debían pagar altos precios por el arrendamiento de las tierras, contaban con una tecnología atrasada, tenían ganado de mala calidad y pasturas con fuertes variaciones estacionales (Bértola, 1991, p. 190).

Dichos tambos, generalmente pertenecían a familias de inmigrantes, especialmente vascos, que arrendaban tierras cerca de Montevideo para producir leche. El ordeñe se hacía en condiciones deficientes. Se ordeñaba a campo o en galpones de ordeñe con pisos de tierra. Para 100 vacas se requería de tres ordeñadores, un apoyador y entre 200 y 300 hectáreas para pastoreo. A esto se sumaba que la producción de leche tenía una fuerte estacionalidad, cayendo fuertemente en el invierno. El rodeo utilizado para la producción de leche estaba compuesto por ganado mestizo Hereford o Shorthorn. Recién en 1906 se había iniciado el mejoramiento del ganado lechero mediante la mestización con animales puros de razas lecheras Normando, Holando y Jersey - y este fue un proceso lento hasta 1920.

La conservación de la leche hasta su traslado también eran deficiente: los establecimientos no poseían sistemas de refrigeración de la leche y tampoco lo tenían los ferrocarriles que la transportaban. El mismo Censo Agropecuario de 1937 sostenía:

\begin{abstract}
El florecimiento de la industria lechera no fue todo lo importante que se esperaba, debido en parte a la falta de una organización adecuada de los mercados de consumo, en particular de los internos, haciéndose en determinados momentos difícil la colocación de toda la producción, y en parte a defectos técnicos y económicos en la explotación de los establecimientos productores que, además de acentuar la dificultad de colocación por la producción abundante en primavera y otoño y escasa en verano e invierno, influyen desfavorablemente en los costos de producción (Censo Agropecuario de 1937, citado por Jacob, 1981, p. 221).
\end{abstract}

Algunas fuentes de la época señalaban que, para 1913, se consumían alrededor de 70000 litros diarios de leche. El precio de la leche era alto debido a los costos de distribución y el atraso en las técnicas de producción (Bertino y Tajam, 2000). 


\section{La mala calidad de la leche: consecuencias sobre la salud pública y propuestas para organizar la producción}

Las características de la producción de leche antes señaladas tuvieron sus severas consecuencias respecto de la calidad del producto. En el Primer Congreso de la Leche (Ministerio de Industrias, 1918) llevado a cabo en Montevideo en 1918 se señalaba a la mala calidad de la leche como responsable de numerosas enfermedades. Morquio ${ }^{8}$ sostenía que (1918, citado por Birn, Cabella, y Pollero, 2010) la leche proveniente de las lechería rurales era toda de mala calidad, extraída y envasada en condiciones defectuosa, sin respetar reglas de higiene y llegaba a las familias muchas horas después del ordeñe. También se señalaba que no había refrigeración ni en los tambos ni en los vagones que trasladaban la leche ${ }^{9}$.

La mala calidad de la leche se relacionaba directamente con la problemática de la salud de Montevideo y se expresaba en mortalidad infantil. Al respecto, Birn, Cabella, y Pollero (2005, p. 143) señalan que "las enfermedades gastrointestinales fueron la principal causa de muerte en los niños menores de un año hasta mediados del siglo XX", es decir que las diarreas explicaban buena parte de la mortalidad infantil de la época. La rápida urbanización de Montevideo, particularmente en el primer tercio del siglo XX, implicó el deterioro de las condiciones sanitarias, de vivienda y hacinamiento de sus habitantes. Esto se reflejó en la crisis de la vivienda y florecimiento de "conventillos"10 y en una red de aguas corrientes y sistema cloacal insuficiente por el crecimiento de la ciudad tanto demográfico como en extensión (Birn et al., 2005, p. 140). Una de las causas de enfermedades gastrointestinales era la infección trasmitida por el agua y los alimentos, especialmente la leche.

8 Luis Morquio fue fundador de la pediatría uruguaya y del Instituto Internacional Americano de Protección a la Infancia en 1927, mundialmente reconocido por su investigación sobre las enfermedades infantiles. Director de la cuna de Asilo de Expósitos y Profesor de la Clínica de Niños de la Facultad de Medicina.

9 La leche que se consumía era mala porque llegaba en malas condiciones. En invierno llegaba bien porque llegaba fría. Los vagones de ferrocarril eran techados y con costado de madera, pero no cerrada. En verano eran un horno. Como es un elemento vivo, la leche llegaba terriblemente contaminada, los microbios se desarrollaban como en un caldo. A eso había que agregarle las infecciones que tenía el ganado como la tuberculosis (Testimonio de José María Ferrari Goudschaal, médico higienista e hijo de Andrés Ferrari Vanoli, fundador de COLE S.A. y CONAPROLE).

10 Así se denominaban a las viviendas colectivas urbanas que albergaban gran cantidad de familias. Generalmente cada familia ocupaba una habitación y los servicios como comedor y baños eran comunes. En otros países son conocidas como casas de inquilinato (Chile) o vecindad (México). 
Frente a la situación sanitaria descrita, en el marco del Primer Congreso de la Leche, se dedicó todo un capítulo a la forma de organización de producción lechera. Se encomendó al ingeniero Agrónomo Arturo Abella un informe sobre "Utilidad de concentrar en manos de sociedades constituidas: industrialmente el comercio de la leche" (Abella, 1918). En este informe se argumentaba sobre la necesidad de centralizar la industrialización de la leche en los lugares próximos a los mercados de consumo:

Nuestro mercado se caracteriza por el gran núcleo consumidor de la Capital, que es dominantey al cual afluye la mayor parte de la producción, y pequeños mercados interiores que participan de las deficiencias del primero. La zona productora se aleja cada vez más de la Capital, obligada por lo que hemos llamado el crédito de la tierra (Abella, 1918, p. 314).

Para hacer frente a esta problemática, dicho informe proponía orientar la acción estatal hacia el fomento de la asociación de los propios productores. Esta propuesta se fundamentaba en que "la experiencia de todos los países productores de importancia, [...] la organización ideal de la venta y de la industrialización de la leche [se encuentra] en los sistemas cooperativos" (Abella, 1918, p. 314). Sostenía que todos los informes del movimiento cooperativo en el extranjero mostraban que el principal efecto de las asociaciones fue la disminución de los gastos de explotación y el mantenimiento regular de los precios. La organización cooperativa permitía, a juicio del informante, agrupar a los productores y consumidores y suprimir a los intermediarios que provocaban los altos precios de la leche. Rechazaba la industrialización a través de la misma municipalidad porque, en ese caso, se estaría creando entre el consumidor y el productor un intermediario de otra especie, a saber, el propio municipio. Llegaba entonces a la conclusión de que:

\section{[...] por medio de la centralización en una usina municipal puede resolverse el problema higiénico y una parte del económico, pero por medio de la asociación entre productores se resuelven todos los aspectos de la cuestión, desde el productor hasta el consumidor, pasando por todos los puntos de orden técnico y económico que comprende este asunto [en cursiva en el original] (Abella, 1918, p. 317).}

Abella hacía referencia a la existencia de la Asociación Nacional de Lechería como organización en base a la cual se podría desarrollar su propuesta y sostenía que el argumento más serio a favor de la higienización de la leche en forma cooperativa 
"es que ese movimiento ya se ha iniciado en el país" (Abella, 1918, p. 319). Luego pasaba a explorar los medios para fomentar la organización de los productores y mencionaba, entre otros: la consolidación de los sindicatos rurales y las sociedades y comisiones de fomento; favorecer el desarrollo de la Asociación Nacional de Lecherías, la contribución del Estado por medio de la propaganda de los técnicos y el contralor racional de la higiene de la industria; la necesidad de solucionar los grandes problemas rurales como la vialidad de la campaña, la difusión del crédito y de la enseñanza y finalmente proponía la obligatoriedad de la higienización de la leche en las ciudades mayores de más de 10000 habitantes.

\section{Esfuerzos por organizar la producción y la comercialización de la leche}

Para responder a los problemas que traía aparejada la mala calidad de la leche y la situación de los productores, durante los años veinte se desarrollaron distintos esfuerzos para organizar la producción y comercialización de la leche. Los esfuerzos se orientaron en dos direcciones. Por una parte, la formación de cooperativas de productores y la creación de usinas pasteurizadoras de leche. Por otra parte, el desarrollo de un cuerpo normativo tanto a nivel municipal como nacional para dar respuesta a la problemática mencionada.

\section{La formación de cooperativas de productores y usinas pasteurizadoras}

La primera lechería donde se tomaron medidas de higiene y pasteurización, se instaló en 1913 con el nombre de Fábrica de Productos Lácteos Kasdorf. Además de la pasteurización de leche, entre otras innovaciones, fabricó y comercializó yogur. Posteriormente, en 1921 se fundó en la Lechería Central Uruguaya que absorbió dos granjas existentes, Sol (1904) y Los Normandos (1908). La firma se integró con los hermanos Kasdorf (Otto, Max y Walter) y otros socios (Irureta Goyena, Echegaray y Antonio M. Grompone). En 1930 las dos compañías en las que participaban, y que tenían en común algunos directivos, se fusionaron en Lechería Central Uruguaya y Productos Kasdorf (Jacob, 1981, p. 222 y ss.).

Los productores lecheros organizados también crearon su propia usina pasteurizadora. Las iniciativas de organización tuvieron su origen en las preocupaciones de los productores remitentes de leche que estaban expuestos al poder 
de los intermediarios y tenían serias dificultades para cobrar lo que enviaban. La leche era enviada a Montevideo por tren a la Estación Central. En "la planchada" la recibían los repartidores que previo el pago de un "conocimiento" -factura-, se les entregaba la leche y luego era transportada en carros tirados por caballos hasta los domicilios de los consumidores. La leche se medía con una medida de medio litro, que era contratada anualmente por la Intendencia Municipal, en caso de no contar con ella podían ser pasibles de una multa y decomiso (Fenocchi, 2000). Así lo relata el hijo de Andrés Ferrari Vanoli, fundador de una de las cooperativas de productores lecheros:

En aquella época, antes de estar la Conaprole y antes de estar las cooperativas que la precedieron (la COLE, Cooperativa de Lecheros, de la que formaba parte mi padre y la Kasdorf), se enviaba la leche a Montevideo donde la recibían los compradores y distribuidores de leche. Era un gremio muy grande, en total dicen que eran más de 100. En ese tiempo llegaba a la Estación Central en vagones y allí se pesaba y la entregaban. ... Los inspectores no daban abasto, también era difícil cobrar, había que venir todos los meses a cobrar, a veces venía uno con el poder de los otros, pero el asunto era cobrar, a veces no se cobraba (Testimonio de José María Ferrari Goudschaal, médico higienista e hijo de Andrés Ferrari Vanoli, fundador de COLE S.A. y Conaprole, 2000).

Algunos productores de pequeños tambos que enviaban leche a Montevideo ${ }^{11}$, comenzaron a organizarse buscando mejorar su actividad. Cuenta Fenocchi (2000) que los productores de la localidad de Cardal eran asesorados por José (Pepe) Rossi y se reunían mensualmente en la localidad de 25 de agosto, donde Rossi tenía un escritorio. Allí trataban temas como la compra de forrajes, arados, enfriadoras, para conservar la leche fresca del ordeñe de la tarde, entre otros. En esas reuniones salían a relucir las dificultades para cobrar la leche remitida puesto que los repartidores aducían que los tarros iban por la mitad o que llegaba cortada ${ }^{12}$. En otras oportunidades

11 Fenocchi (2000) menciona entre otros a su padre Francisco Fenocchi, los hermanos Mollo, las familias Lanz, Machín, Folgar, los hermanos Díaz, Lemos, Scalabrino, Del Valle Herrera, Rapallini, Sandro. También los hermanos Steiner tenían un gran tambo cruzando el río Santa Lucía. De San José enviaban Bide, A. Facello, Methol, Hernandorena, Dionisio Cruz y otros.

12 Fenocchi (2000) cuenta que además de su padre Francisco Fenocchi "el proyecto fue apoyado, entre otros, por los señores S. Marino, M. Álvarez, M. Gesto, A. Facello, José García, Julio Mollo, G. Rebella, Jesús Moreira, J. F. Cuadro, los hermanos Cluzet y Glague. Para reunirse alquilaron un local en la calle Yaguarón entre Nicaragua y Venezuela". 
argumentaban que la leche había sobrado y que debieron rematarla a muy bajo precio. Esta situación motivó que los productores comenzaran a concebir la idea de formar una sociedad de tamberos y lecheros bajo la forma cooperativa ${ }^{13}$.

De acuerdo al testimonio de Pelayo Arocena, hijo de uno de los fundadores de COLE: "Poco a poco la gente fue tomando conciencia de las ventajas de asociarse y así se formó la primera cooperativa de productores lecheros a la que bautizaron COLE, Cooperativa de Lecherías Sociedad Anónima"14. Las obras para la instalación de la usina de la COLE comenzaron en 1926 y la planta fue inaugurada el 18 de julio de 192815 . Para la puesta en funcionamiento de la COLE se compró maquinaria AlfaLaval de Suecia para los equipos pasteurizadores, Cherry-Burrell de los EE.UU. para los equipos de lavado, Westfalia y otras para las diferentes operaciones (testimonio de Pelayo Arocena).

La COLE tuvo dificultades para amortizar la gran inversión que hizo en maquinaria puesto que debía competir con la leche cruda producida en los tambos urbanos a un costo bastante inferior. Situación que tornó insostenible a la empresa en la medida que los poderes públicos no se ponían de acuerdo en la exigencia de la obligatoriedad de la pasteurización de la leche.

13 La solución cooperativa contaba con profusos antecedentes, aunque muchos de ellos no llegaron a concretarse. Muchas de ellas vinculadas a la educación, entre otras iniciativas propuestas en años anteriores se destacan: la creación de las Estaciones Agronómicas de Paysandú y Salto con usinas cooperativas (1926); de la Escuela de lechería en Colonia con contribución de la Sociedad de Fomento Rural (1926); la Escuela Agronómica de Cerro Largo con instalación frigorífica para uso de los productores (1929); y las Escuelas Industriales con usinas de pasteurización de leche para la enseñanza y como base de cooperativas de lechería (1930) (Bertino y Tajam, 2000, pp. 17-18).

14 No fue hasta 1941 cuando se aprobó la Ley 10008 de cooperativas agrarias que las organizaciones de productores van a tomar la forma jurídica cooperativa. Hasta entonces y, como se verá más adelante, con la sola excepción de Conaprole, las cooperativas funcionaron bajo la forma de sociedades anónimas. Otro tipo de sociedades cooperativas tuvieron que esperar hasta 1946 cuando se aprobó la Ley No 10.761 de sociedades cooperativas. El funcionamiento de las cooperativas bajo la forma de sociedades anónimas debió de ser contemplado por el Artículo 17 que facilitaba a las sociedades anónimas a convertirse en cooperativas con el acuerdo de la mayoría de los asociados.

15 De acuerdo al Testimonio de Pelayo Arocena, entre los fundadores de la COLE figuran distintas personalidades como Diego Arocena Capurro y Jorge Seré. Este último sería posteriormente homenajeado por CONAPROLE al denominar a la antigua planta de la COLE con su nombre: Usina No 2 lng. Jorge Seré Ibarra. También participaron de la fundación de la cooperativa Andrés Pastorino, Armand Ugón, Methol, Hernandorena, Bertoni, Dionisio Cruz y Francisco Fenocchi (Fenocchi, 2000). 


\section{La evolución del marco normativo de la pasteurización}

Desde que se celebró el Primer Congreso de la Leche en 1918 la discusión sobre la obligatoriedad de la pasteurización había estado presente en el debate político de la época. A comienzos de la década de 1920 se presentó un proyecto de ley sobre la obligatoriedad de la pasteurización de la leche. En efecto, los diputados Manuel Albo ${ }^{16}$ y Ernesto Bauzá17 (28ª Legislatura) presentaron en abril de 1923 un proyecto sobre la obligatoriedad de higienización y pasteurización de la leche de consumo para la población de ciudades de más de 5000 habitantes. Este proyecto fue estudiado por la Comisión de Higiene y votado el 31 de agosto de 1926 por la Cámara de Diputados, pero el Senado nunca lo trató (Ferrari Goudschaal, s.f., p. 132).

Recién en 1927 se aprobó la primera reglamentación sobre la obligatoriedad de la higienización de la leche. La Ordenanza de Higienización de la Leche en Montevideo se aprobó por el Concejo Departamental de Montevideo el 29 de agosto de 1927 y se publicó en el Digesto Municipal en el año 1930. Fue fundamental el impulso de Enrique Claveaux, médico dedicado a la higiene pública preocupado por la calidad de leche que se tomaba en Montevideo. La ordenanza regulaba la producción de leche en los tambos, estableciendo medidas de higiene del tambo -locales, condiciones de salud animal y del personal con carné de salud-, la obtención, filtrado y enfriamiento de la leche. También se preocupaba por el transporte aconsejando el uso de vagones refrigerados, la recepción centralizada, los controles por técnicos municipales y el fraccionamiento y distribución en envases de vidrios inviolables de uno y de medio litro (Ferrari Goudschaal, s.f., p. 135).

A pesar de que la Ordenanza de 1927 establecía la obligatoriedad de la pasteurización, no fue hasta el 25 de abril de 1933 que se decretó que la Intendencia de Montevideo "pondrá en vigencia de inmediato la ordenanza sobre pasteurización de la leche". Una Ley aprobada en diciembre de 1929 establecía que a partir del 1 de enero de 1934 se debía hacer efectiva la ordenanza sobre la pasteurización de la leche (Jacob, 1981, pp. 223-224).

Posteriormente, en la búsqueda por solucionar el problema de la leche se intentó con la fijación del precio. En diciembre de 1933 se aprobó la Ley 9175 por la que "Se establecen disposiciones sobre higienización y pasteurización de la leche para la venta en Montevideo". El artículo 1 establecía en \$ 65 milésimos el litro, el

16 Manuel Albo (1886-1935), representante por Montevideo del Partido Nacional.

17 Ernesto Bauzá, representante por Cerro Largo del Partido Colorado, autor del trabajo: "Abastecimiento de leche higiénica para las ciudades", donde se proponen medidas de higiene para la leche y se sugiere la creación de cooperativas para su producción. 
precio mínimo que deberían pagar las usinas de pasteurización; y en el artículo 5, que a partir del 1 de enero de 1934 se haría efectiva la ordenanza sobre higienización y pasteurización de la leche. Luego, en febrero de 1935 se aprobó la Ley 9462 por la que "Se fija el precio que las Usinas Pasteurizadoras deben pagar al productor de leche y se dictan otras disposiciones en beneficio de la industria". Además de fijar el precio de la leche al productor, se establecían las contribuciones, el costo de pasteurización y el precio final al consumidor, además de ratificar las limitaciones en cuanto al número de usinas establecidas por la Intendencia de Montevideo (Bertino y Tajam, 2000, p. 21). Sin embargo, y como se ha visto, al no ser compulsiva la pasteurización los productores que invirtieron en la construcción de usinas pasteurizadoras debieron competir con el precio inferior de la leche cruda. De acuerdo a la opinión de los representantes de las usinas:

La ley de febrero del corriente año, nos colocó de nuevo en inferioridad de condiciones ya que se estableció una competencia que nos ha traído a una situación desesperante, pues mientras cumplíamos la ley al pie de la letra, las llamadas usinas chicas que no lo hacían, nos quitaban día a día, litrajes de venta, colocando a nuestros productores en una situación tan difícil que llegó a ser ruinosa y a la que puso fin la ley actual. (El País, Montevideo, 30/12/1935, p. 13. Ecos del homenaje a Don Pedro Sáenz. Discurso del Ing. A. Bessio).

Frente a este contexto, uno de los últimos movimientos del período fue la fusión entre las usinas pasteurizadoras más grandes. En ocasión del homenaje de despedida a Pedro Sáenz, presidente de COLE (período 1934-1935), se hace alusión a la fusión con la otra usina pasteurizadora grande:

Uno de los hechos más salientes de vuestro mandato, ha sido el haber llegado a una fusión con la enemiga de antes, la Lechería Central Uruguaya, lo que ha permitido terminar con una competencia que para ambas Usinas fué de grandes perjuicios materiales durante varios años... (El País, Montevideo, 30/12/1935, p. 13. Ecos del homenaje a Don Pedro Sáenz. Discurso del Ing. A. Bessio).

Esta situación obligó a tomar el problema de la producción de la leche y su procesamiento en conjunto. La posibilidad de la formación de una cooperativa se presentó como una de las soluciones posibles. Por una parte, se entroncaba con el reclamo 
por la organización de la lechería en cooperativas de comienzos del siglo XX: cooperativas lácteas que protegieran a los productores, eliminaran a los intermediarios y controlaran la calidad (Bertino y Tajam, 2000, p. 17). Además, tal como se mostró, la solución cooperativa contaba con profusos antecedentes tanto a nivel nacional como internacional.

Finalmente, la solución planteada conjugó la movilización de los productores y sus preocupaciones y la acción del gobierno. Un testimonio oral de uno de los hijos de los protagonistas cuenta que la solución definitiva, la creación de una cooperativa con el monopolio de la industrialización, distribución y comercialización, fue propuesta por el presidente de la época Gabriel Terra ${ }^{18}$ y contó con el asesoramiento de uno de los fundadores de la COLE S.A. El presidente Terra planteó la creación de una cooperativa de productores y Arocena Capurro le propuso que esta cooperativa se hiciera cargo de los activos de la COLE S.A. y contara con el monopolio dentro de la ciudad de Montevideo, a la vez que sugirió la prohibición de los tambos urbanos que vendían leche cruda en la ciudad ${ }^{19}$.

18 Gabriel Terra (1873-1942), dirigente del P. Colorado, fue electo como presidente de la República Oriental del Uruguay para el período 1931-1935. Como se verá más adelante, de origen batllista paulatinamente se fue distanciando del sector batllista para líder su propio sector. El 31 de marzo de 1933, con el apoyo de los sectores opositores al reformismo batllista, dio un Golpe de Estado.

19 El intercambio entre el presidente Terra y Arocena Capurro es relatado por su hijo, Pelayo Arocena Vázquez, de la siguiente manera: "En 1934, el Dr. Gabriel Terra, encargó al Dr. Arocena que buscase la forma de remediar la situación casi angustiosa en que se encontraba la cooperativa [se refiere a COLE]. Por intermedio de Arturo Terra Arocena (sobrino de Terra y primo hermano de Arocena) se solicitó una entrevista con el presidente. Paso a repetir el diálogo según me lo contó el Dr. Arocena: - Sr. presidente, vengo a hablar con Ud. para... - Ya lo sé, Dr.... - me interrumpió el Dr. Terra -, Ud. viene por esto. Y sacó de un cajón un legajo importante y me lo dio al tiempo que me decía: - Ud. es abogado, acá está el proyecto de una nueva cooperativa. Estúdielo y venga a verme dentro de quince días y me da su parecer bien clarito, sin esconder nada. A los quince días me recibió nuevamente y me pidió mi opinión. -Sr. presidente, a esto le faltan solamente tres cosas. 1) Que la nueva cooperativa se haga cargo del activo y el pasivo de la COLE para no dejar desamparados a un número importante de productores. 2) Que se prohíban los tambos dentro de la ciudad y la venta de leche cruda y, por último, 3) Que se le dé el monopolio del mercado de la leche en una zona adecuada por un plazo no menor de treinta o cuarenta años para que se consolide convenientemente. - ¿Y después? - Después, que tenga que competir con los que le salgan al paso. Será para bien de todos" (Testimonio de Pelayo Arocena Vásquez). 


\section{Creación de Conaprole: movilización de productores y políticas públicas}

A pesar de todos los esfuerzos realizados, y algunos que se concretaron, a lo largo de los años veinte y comienzos de los años treinta, tanto por los productores lecheros como por los poderes públicos la situación permanecía sin cambios. La calidad de la leche seguía siendo mala, las enfermedades gastrointestinales asolaban a la población infantil y la situación de los productores lecheros era insostenible. Fue recién con la creación de Conaprole en diciembre de 1935 y el comienzo de su producción en junio de 1936 que se lograron revertir y solucionar los problemas expuestos. Para ello fue fundamental la movilización de los productores y la acción de los poderes públicos.

\section{La movilización de los productores: impulsores y opositores}

La creación de una cooperativa de productores no es explicable sin el decidido accionar de la Asociación Nacional de Productores de Leche (ANPL). Esta institución fue creada en 1933 en la localidad de San Ramón, que formaba parte de la cuenca lechera de Montevideo, y a pesar de distar mucho de ser nacional agrupó desde sus inicios a un conjunto de tamberos que hicieron posible la cooperativa (Supervielle, 1986). La entidad gremial fue fundada el 23 de abril de 1933 para "amparar y estimular los intereses de todo orden del gremio de productores de leche". Fue una de las primeras agrupaciones para combatir "el aislamiento del productor, retenido en su tambo por la dura exigencia diaria del trabajo y naturalmente alejado de quienes se ocupaban del mismo quehacer" (Actas del Directorio de Conaprole, Libro 1, p. 274). Al ingresar el tema en el Parlamento, la Asociación hizo llegar este telegrama.

Canelones, octubre 12 de 1935. Presidente de La Asamblea General, Dr. Alfredo Navarro. Palacio Legislativo. Montevideo. Asociación Nacional de Productores de Leche en conocimiento que el Poder Ejecutivo envió un mensaje proyecto creando la Cooperativa Nacional de Lechería, que contempla legítimas aspiraciones inmensa mayoría gremio, ruega señor presidente interponga su valiosa influencia a fin Cámara de Representantes y Senado se aboquen de inmediato estudio y sanción proyecto que pondrá término situación angustiosa productores en virtud hechos conocidos. Saludan a usted. Atentamente Juan Mollo, presidente - Pedro Gatti, secretario. 
Pero también se constituyeron organizaciones ad hoc. Por ejemplo, se conformó un Comité de Emergencia de Productores de Leche. Como dato importante tenía su asiento en la calle Uruguay 864, sede de la Asociación Rural del Uruguay (ARU) ${ }^{20}$. El comité estaba presidido por Andrés Pastorino, futuro presidente de Conaprole. Esta organización, en un aviso publicado en el diario El Día, denuncia que los opositores al proyecto y que pertenecen a distintas organizaciones como Asociación General de Tamberos y Lecheros del Uruguay, Agrupación Nacional de Instituciones Lecheras y Afines, Sociedad comercial y comanditaria Usina Alianza Unión y La Nena, Sociedad Unión de Lecheros y Tamberos, y Federación de Comerciantes e industriales del Uruguay, son, en su inmensa mayoría, repartidores de leche y no productores (El Día, 1935, p. 13).

Para mostrar que ellos representaban el sentir de los productores lecheros publicaron un aviso en el diario El País. El artículo incluía las firmas de productores lecheros, el número de matrícula, la localidad, el promedio de leche remitida el año anterior y la usina a la que remitía (Central, COLE, Mercado Cooperativo, La Palma). Entre las firmas figuraban los médicos higienistas y productores de leche como el ya nombrado Andrés Pastorino y el Dr. Julio Nin y Silva, así como el tambo de Arocena, Pastorino y Steiner.

El proyecto emanado de la Comisión presidida por el señor Ministro de Ganadería y Agricultura, al contemplar las aspiraciones de los productores de leche, creando la COOPERATIVA NACIONAL, centralizando la pasteurización en una usina y valorizando la leche para industrializar, cuenta con nuestro más entusiasta apoyo y lo prestigiaremos a efecto de que sea convertido en Ley a la brevedad posible. (El País, 1935, p. 13).

Contaba también con el respaldo de Mercado Cooperativo de Leche S.A. que publicó un aviso en la prensa de Montevideo en el cual manifestaba que:

La solución definitiva es necesario buscarla en la coordinación de ideas de los verdaderos interesados. De acuerdo con tales ideas, declaramos que la fórmula de la Agrupación General de Productores cuenta con nuestro apoyo. (El País, 1935, p. 10).

20 La Asociación Rural del Uruguay (ARU) fue fundada en 1871 al impulso de las fracciones modernizantes de los ganaderos y cumplió un papel fundamental en la difusión del alambramiento y del mejoramiento del ganado a través de la incorporación de las razas inglesas. Desde entonces cumple una función importante en el mejoramiento de las razas llevando los registros genealógicos y efectuando anualmente exposiciones ganaderas cuyos discursos inaugurales son importante definiciones de política agropecuaria. 
Sin embargo, y pese a todas estas manifestaciones de apoyo, hay que señalar también que el día 21 de octubre de 1935 se constituyó la Agrupación Nacional de Instituciones Lecheras y Afines contra el monopolio de la leche, autodenominándose como agrupación de entidades afines a la industria lechera del país. En las páginas del diario El Día, de orientación batllista y por tanto opositor al gobierno de Terra, se daba cuenta de las acciones de esta organización.

Esta agrupación ha resuelto realizar una gran Asamblea el día jueves 24 de octubre a la hora 13 [...] a la que desde ya quedan invitados todos los productores de leche, que teniendo una visión clara de los perjuicios que a todos acarrearía el monopolio de la leche, tal cual lo ha planteado el proyecto que se elevará dentro de breves días a la Cámara de Representantes, se crean en el deber de concurrir. (El Día, 1935, p. 4.).

Conjuntamente con la realización de la citada Asamblea se organizaron manifestaciones públicas contra el proyecto de creación de la cooperativa ${ }^{21}$.

Como se verá más adelante, primó la postura de los partidarios del proyecto que lo vivieron como un triunfo del gremio. Refiriéndose a la ley aprobada Bessio de la COLE S.A. manifestaba que era:

[...] una ley que había sido elaborada por personas sanas, con amplio espíritu de justicia, con profundos conocimientos técnicos, con esa ley que iba a colocar al productor en una situación de prosperidad; que permitiría a. los repartidores estar en las mismas condiciones, terminando así con la competencia ruinosa en que estaban colocados; por la que el modesto consumidor podría adquirir el más necesario de los alimentos a un precio muy reducido, y el resto de los consumidores adquirirían un producto perfectamente higiénico a un precio no más elevado del que habían estado pagando, y una ley, en fin por la que todos los obreros y empleados de las Usinas pasteurizadoras podrían tener trabajo seguro, Ilevando la tranquilidad a sus hogares, tranquilidad a que tienen derecho todos aquellos que cumplen sus obligaciones! (El País, 1935, p. 13).

21 El diario El Día da cuenta de las mismas en dos destacados artículos: "La protesta contra el proyecto de cooperativas de lecherías" (El Día, 1935, p. 9) y "Fue grandiosa la manifestación de protesta" $(1935$, p. 8). 
Además, se continuaron organizando como productores para integrar el directorio de la cooperativa, tal como se daba cuenta en el siguiente artículo:

En el día de hoy debe celebrarse una importante reunión en Canelones, a las 10 de la mañana. Esta reunión fué proyectada en la Asamblea que celebró la Gremial de Productores el sábado último y cuyo resultado lo hicimos conocer de nuestros lectores. En esa Asamblea se dijo que era conveniente y así ser resolvió, la armonía del gremio a los efectos de la integración del Directorio de la Cooperativa y que a ese fin debieran reunirse las directivas de todas las organizaciones gremiales, sin excepción. (El País, 1935, p. 10).

\section{El rol de las políticas públicas para la creación de Conaprole 22}

No obstante, a pesar de la movilización de los productores, la cooperativa no habría podido crearse sin el decisivo apoyo de los poderes públicos. Desde los años veinte el tema de las cooperativas agropecuarias apareció frecuentemente en la agenda legislativa ${ }^{23}$.

La propuesta de crear una cooperativa para solucionar el problema de la leche ya había sido planteada en 1934 por el diputado Arturo Wilson ${ }^{24}$. Él planteaba la intervención del Estado centralizando la industrialización de la leche y la constitución de una cooperativa nacional de lechería y venta de productos de granja (Jacob, 1981, p. 224). Sin embargo, este proyecto no prosperó, entre otras cosas, porque el espectro político estaba polarizado entre quienes defendían la intervención estatal y quienes se oponían a ella. Desde comienzos del siglo XX el Estado uruguayo había desarrollado políticas de intervencionismo estatal a partir de los gobiernos del presidente José Batlle y Ordóñez ${ }^{25}$. El enfrentamiento entre los sectores conservadores opuestos a la intervención del Estado y los sectores batllistas condujo a una polarización política y a

22 Este apartado toma como base el trabajo de Martí (2013), donde se puede profundizar sobre el rol cumplido por las políticas públicas.

23 Vicens (1941, pp. 176-177) sostenía que entre 1920 y la aprobación de la Ley 10008 de cooperativas agropecuarias en 1941, se presentaron alrededor de veinte proyectos relacionado son las sociedades cooperativas.

24 Este diputado participó también de la Comisión que formuló el proyecto de creación de CONAPROLE (Diario de Sesiones de la Cámara de Representantes, 1935, p. 172).

25 José Batlle y Ordóñez (1856-1929), dos veces presidente de la República (1903-1907 y 1911 1915) y dirigente del Partido Colorado, líder del sector batllista. 
la amenaza constante de un quiebre institucional. A esto se sumaba que la Constitución de 1918 estableció un Poder Ejecutivo bicéfalo: el presidente de la República, presidido por Gabriel Terra, tenía a su cargo la seguridad, defensa y relaciones exteriores y el Consejo Nacional de Administración (CNA), presidido por Juan P. Fabini (1876-1962), perteneciente al sector batllista, tenía a su cargo la educación, obras públicas, trabajo, industria, hacienda y salud pública.

Esta división trajo aparejada dos visiones de cómo hacer frente a la crisis. El Consejo Nacional de Administración (CNA), con el apoyo del batllismo y del nacionalismo independiente ${ }^{26}$, implementó una política económica decididamente intervencionista ${ }^{27}$. Las políticas del CNA concitaron la oposición de diversos sectores que se sintieron perjudicados por las mismas (Jacob, 1981). La situación derivó en un fuerte enfrentamiento entre los batllistas y nacionalistas independientes que respaldaban las medidas del CNA y los herreristas ${ }^{28}$ y sectores no batllistas del Partido Colorado opuestos al intervencionismo estatal del CNA.

El enfrentamiento entre estas posturas desembocó en el golpe de Estado del 31 de marzo de 1933. Para dar el golpe, el presidente Terra contó con la ayuda de la policía y la pasividad del ejército, además del apoyo político de diversos sectores: los grupos no batllistas del Partido Colorado y el herrerismo dentro del Partido Nacional. También contó con el apoyo de las "fuerzas vivas" que se habían agrupado unos años atrás en el Comité de Vigilancia Económica -integrado por la Federación Rural, la Unión Industrial del Uruguay y diversas entidades que agrupaban el comercio mayorista y minorista-. En contra del golpe de Estado se manifestaron los sectores batllistas, los nacionalistas independientes, los radicales blancos ${ }^{29}$, los socialistas y comunistas. En tanto fue poco clara la posición de la Unión Cívica. Por su parte, la oposición del movimiento sindical careció de organización y la oposición de la Universidad de la República no tuvo gran impacto.

26 El Partido Nacional Independiente es una escisión de sectores opositores al liderazgo de Luis Alberto de Herrera en el Partido Nacional.

27 Entre las medidas proteccionistas se pueden mencionar: la aprobación de impuestos extraordinarios para las importaciones de bienes suntuarios o la ley de privilegios industriales de 1930 . Como medidas que reflejan el avance de la estatización se destacan la creación de ANCAP (Administración Nacional de Combustibles, Alcohol y Portland) y la ley que permitía la expropiación de las compañías telefónicas privadas y el monopolio estatal de las comunicaciones telefónicas dando lugar a la transformación de UTE en Usinas y Teléfonos del Estado, ambas de 1931.

28 Sector del Partido Nacional liderado por Luis Alberto de Herrera (1873-1959).

29 Sector de origen nacionalista orientado por Lorenzo Carnelli (1887-1960) que constituyó el Partido Blanco Radical. 
Con el golpe de Estado el presidente de la República tomó la conducción económica y financiera del país y convocó a la elección de una Convención Constituyente con el objetivo de reformar la constitución ${ }^{30}$. La nueva Constitución, si bien puso frenos a la intervención del Estado, estableciendo mayorías especiales para la creación de algunos organismos, no significó una ruptura con las tendencias manifestadas desde principio de siglo y consagró al Estado como protector y garante de derechos sociales.

La Convención eligió la fórmula presidencial Gabriel Terra y Alfredo Navarro el 21 de marzo de 1934. La Constitución se sometió a plebiscito el 19 de abril 1934. Junto con el plebiscito de la reforma constitucional se votó la integración del Parlamento y los organismos electorales ${ }^{31}$.

El gobierno de Gabriel Terra se caracterizó por un conservadurismo moderado y pragmático. Si bien las políticas fueron favorables a los sectores ganaderos, las empresas extranjeras y los grupos financieros, el contexto internacional desfavorable obligó a una intervención estatal más importante que la prevista originalmente el proteccionismo y el dirigismo económico ${ }^{32}$. En síntesis desarrolló políticas que reafirmaron la presencia del Estado pero como apoyo a la iniciativa privada (Nahum et al., 1988, p. 31).

La propuesta de creación de una cooperativa de productores lecheros fue reflejo de esta postura del terrismo. Al crear la cooperativa el Estado intervenía suministrando el capital y asegurando las condiciones de mercado para la nueva empresa diferente a las empresas estatales creadas por el batllismo.

El proyecto de creación de la cooperativa fue liderado por el Ministro de Ganadería y Agricultura de la época y quien convocó a una comisión especial para redactarlo. Fue presentado ante el Plenario de la Cámara de Representantes el 29 de octubre de 1935, firmado por el presidente de la República Gabriel Terra y su ministro César G. Gutiérrez. En la fundamentación del proyecto, el mismo ministro argumentó por la creación de una cooperativa particular.

30 La elección de la constituyente se realizó el 25 de junio de 1933 con una importante abstención de batllistas, nacionalistas independientes, blancos radicales y socialistas; y diversas denuncias de fraude. Esta Constitución fue reflejo de la particular coyuntura de alianza entre terristas y herreristas. Entre otros cambios la Constitución establecía un régimen parlamentario atenuado. El P.E. tendría al frente al presidente de la República (artículo 149). En tanto el Poder Legislativo sería bicameral, con un Senado de 30 miembros, 15 de los cuáles corresponderían a la mayoría y otros 15 a la minoría (artículos 86 y 87) y la Cámara de Representantes de 99 miembros con representación proporcional (artículo 78).

31 Los batllistas y nacionalistas independientes nuevamente llamaron a la abstención y concurrieron a votar poco más del $50 \%$ de los habilitados que por amplia mayoría aprobaron la nueva constitución.

32 En este sentido se puede mencionar la Ley Baltar aprobada en 1936 que, sin derogar los monopolios existentes, impedía implantar nuevos. 
[...] dentro del cooperativismo hemos elegido la fórmula de la "régie coopérative"; aquella que ha surgido en Bélgica en el año 1869 con la "Régie Coopérative de Crédits" y que desde ese primer ensayo, puede decirse que no ha registrado ningún fracaso (Diario de Sesiones de la Cámara de Representantes, 1935, p. 175).

El propio ministro abundaba en más detalles y sostenía que se trataba de una régie coopérative pues nacía de una ley, eran solamente los productores los que tendrían la dirección de la misma, el Estado no intervendría en la administración y renunciaba a toda intervención que no fuera la de un síndico designado por el Banco de la República.

El proyecto se aprobó por la Ley 9526 que creaba la Cooperativa Nacional de Productores de Leche. En su artículo 1 establecía que "Toda la leche destinada al consumo de la población de Montevideo, que no reúna las condiciones exigidas por las ordenanzas respectivas para el expendio de leche cruda, será higienizada y pasteurizada en la o las usinas de la C.N.P.L. [...] La C.N.P.L. explotará, bajo el indicado régimen de libre concurrencia, las distintas ramas de la industria lechera y sus derivados".

La creación se hizo a través de la expropiación y fusión de las anteriores plantas pasteurizadoras de leche ${ }^{33}$. Se transferían sus instalaciones y se incorporaban sus trabajadores y sus marcas. Los activos fueron adquiridos por el Estado uruguayo y luego traspasados a Conaprole quien asumió esa deuda.

La organización que se creó contemplaba la participación de los propios productores y una fuerte intervención estatal. Los productores eran los dueños de la cooperativa. En el artículo 2 se establecía que "Todo productor de leche, de cualquier zona del país, podrá hacerse miembro de la C.N.P.L., remitiéndole su producción". Además, era dirigida por un Directorio compuesto de cinco titulares y diez suplentes, elegidos por los productores que tuvieran al menos un año de antigüedad. La elección del Directorio debía ser instrumentada por la Corte Electoral. No obstante, a diferencia de la concepción democrática establecida por los principios históricos del cooperativismo de un hombre-un voto, la ley ponderaba el voto de los productores de acuerdo a la leche remitida (artículo 18). Junto al Directorio en la el acto eleccionario se debía elegir la Asamblea de Productores constituida veintinueve delegados (artículo 25).

33 El artículo 4 indicaba las industrias a expropiar: "Cooperativas de Lecherías S. A.", "Lechería Central Uruguaya Kasdorf S. A.", "Mercado Cooperativo S. A.", "La Palma S. A.", "La Nena", "Alianza de Tamberos y Lecheros La Unión". 
A su vez, la intervención del Estado en la cooperativa era muy amplia. En primer lugar, otorgaba el monopolio legal de la industrialización, distribución y comercialización de leche en la ciudad de Montevideo. Por otra parte, además de la intervención de la Corte Electoral para la elección de las autoridades, la ley instituía en su artículo 23 la figura de un síndico nombrado por el Banco de la República responsable de la fiscalización. También se vio reflejada la intervención en la fijación de precios máximos y mínimos de la leche (artículos 6 y 7) así como cierta cuota de leche que debía destinarse a los Servicios de Salud Pública y al Consejo del Niño (artículo 3). Esta intervención estatal se incrementó unos años después con la aprobación de la Ley 10707 del 9 de enero de 1946 que regulaba la ampliación y funcionamiento de Conaprole y aumentaba el número de directores con un representante del gobierno nacional y otro del gobierno municipal ${ }^{34}$.

\section{Conclusión}

La creación de Conaprole terminó por dar respuesta al llamado problema de la leche. Este problema tenía dos aspectos, por un lado, la mala calidad de la leche consumida y las consecuencias sanitarias en enfermedades y mortalidad infantil en Montevideo a principios del siglo XX. Por otra parte, el problema de los productores lecheros que se encontraban en manos de los intermediarios que pagaban poco y mal la leche recibida y la industria y sus costos que hacían casi inviable su actividad lechera.

Esta situación fue tematizada como un problema político y por tanto se exigía la intervención del Estado. Sin embargo, las respuestas fueron por tres carriles diferentes. En primer lugar, a través de la inversión privada se instalaron plantes industrializadores para la pasteurización de la leche. En segundo lugar, los productores organizados en cooperativas crearon su propia usina pasteurizadora como forma de superar el poder de los intermediarios y valorizar su producción. Como se ha mostrado, los productores comenzaron organizándose en cooperativas sui generis, la más importante era COLE S.A., que instaló una de las primeras y más modernas plantas pasteurizadoras. Sin embargo, la fuerte inversión en maquinaria realizada tanto por las cooperativas como por las industrias privadas no pudo ser amortizada por la competencia de la leche cruda que se vendía en Montevideo a costos sensiblemente menores. Esto porque, el tercer esfuerzo también frustráneo, fue la acción de los poderes públicos para establecer la obligatoriedad de la pasteurización. El marco normativo que se ensayó

34 En el artículo 12 se establece que "El Directorio de la CONAPROLE además de los cinco miembros que establece el artículo 17 de la ley número 9.526, de diciembre 14 de 1935, se integrará con dos miembros más: uno designado por el Poder Ejecutivo y otro por la Intendencia Municipal de Montevideo, que se renovarán en los mismos plazos que los otros Directores". 
para lograr la pasteurización primero apuntó a la obligatoriedad, aunque nunca se puso en práctica y luego lo intentó con la fijación el precio.

La solución llegó finalmente cuando se tomó el problema de la producción conjuntamente con el procesamiento. Para la formación de Conaprole confluyeron los esfuerzos de los productores preocupados por las condiciones de producción con las medidas de política pública que apuntaban al problema de la calidad de la leche.

Para llegar a esta solución fue fundamental el impulso de las organizaciones de productores lecheros que se organizaron gremialmente. Establecieron asociaciones para la defensa gremial, la más importante fue la Asociación Nacional de Productores de Leche, creada en 1933 en la localidad de San Ramón y que funciona hasta nuestros días. El respaldo de esta organización fue fundamental para impulsar el proyecto de creación de Conaprole. También organizaron coyunturalmente para respaldar la aprobación de la ley. Por una parte, se movilizaron en defensa el proyecto de ley frente a los detractores y, por otra, presionaron sobre los legisladores mostrando que ellos expresaban el verdadero sentir del gremio de productores lecheros.

La participación estatal también será determinante. En primer lugar, para crear la primera cooperativa con reconocimiento legal. A través de la Ley 9526 se creó una cooperativa de productores lecheros a la que se le concedió el monopolio de la industrialización y la comercialización de la leche en la ciudad de Montevideo. Esta creación de una cooperativa con apoyo estatal obedece a la particular coyuntura política de la época. Luego de tres décadas de avance del Estado, el Golpe de Estado de 1931, frenó el aumento del intervencionismo, aunque sin que esto significara el retiro del Estado. La creación de la cooperativa reafirmó la presencia del Estado, pero ahora como apoyo de la iniciativa privada. La intervención del Estado tuvo como objetivo supervisar y controlar a la cooperativa que debía dar respuesta a los problemas públicos: la situación de los productores lecheros y la calidad de la leche. Para ello se creó como una régie coopérative, una organización híbrida con participación del Estado y los productores ${ }^{35}$. Se trataba de una "empresa de derecho público no estatal de tipo cooperativo". Se pueden señalar como características más sobresalientes: a) era creada por Ley, b) sus finanzas siempre estuvieron separadas del presupuesto del Estado, c) los socios fueron los productores, d) todo productor de leche pudo

35 El caso de Conaprole se correspondería se correspondería con las ideas propuestas por Spear $(2010,2011)$ de cooperativas híbridas y procesos de hibridización. En particular las ideas de "membership adaptation" y "governance deficiencies" (Spear, 2010) puesto que la ley de creación de Conaprole se aparta del tipo ideal cooperativo al establecer una organización mixta con participación en su gobierno del Estado y por no respetar el principio democrático de un socio un voto al ponderar los votos de acuerdo a la cantidad de leche remitida. Esta discusión se puede profundizar en Martí (2014). 
hacerse miembro de la cooperativa, y e) parte de las utilidades fueron distribuidas entre quienes remitían la leche en proporción a los litros enviados por cada productor durante el ejercicio (Martí, 2014, p. 101).

Conaprole sintetiza un proceso que se nutre desde arriba y desde abajo. La creación obedece a la formulación de una política gubernamental ya que su creación y su posterior desarrollo fue resultado de una política pública en un momento de freno del avance del intervencionismo del Estado. A su vez esta solución respondía a la acción de los productores organizados y sus exigencias reivindicativas. La relativa autonomía de la organización cooperativa fue consecuencias de la lucha y movilización de los productores organizados.

La solución cooperativa se mostró particularmente eficiente desde el momento que el tema de la calidad de la leche y la situación de sus productores desapareció de la agenda pública. Sin embargo, trabajos posteriores deberían avanzar la programación de la solución y profundizar en la implementación de la solución cooperativa y sus consecuencias. Interesa conocer las consecuencias en términos de la mejora de la calidad de la leche y el progreso en la situación de los productores ${ }^{36}$.

Además, la ley de Conaprole, abrió el camino para el reconocimiento estatal de las cooperativas. Seis años después de la creación de Conaprole se aprobó la Ley 10008 de Cooperativas agrarias y más de diez años después se aprobó la Ley 10761 de Sociedades Cooperativas, que servirá de marco legal al cooperativismo hasta la aprobación de la Ley General de Cooperativas 18407 de 2008. Esto nos lleva a plantearnos preguntas que ameritan investigaciones posteriores. En primer lugar, sería necesario identificar otras experiencias históricas de promoción estatal de las cooperativas y cómo se combinaron con la movilización de los actores sociales. En segundo lugar, cabe formularse la pregunta de por qué el Estado uruguayo opta por las cooperativas para desplegar sus políticas públicas. Así como cuáles son los factores llevan al Estado a optar por las cooperativas y qué objetivo persiguen las políticas públicas que promueven cooperativas. A estas preguntas relacionadas con el accionar estatal podríamos agregar algunas interrogantes referidas a las propias cooperativas promovidas desde el Estado. Sería particularmente interesante indagar en cómo condiciona la promoción estatal el desarrollo de las cooperativas, tanto en lo referido a su gestión como al gobierno de estas experiencias.

Cómo se puede apreciar, más allá del caso concreto de la lechería en Uruguay a comienzos del siglo XX y la creación de Conaprole, el estudio permite plantear interesantes líneas de trabajo que ponen en relación las respuestas del mercado, las cooperativas y el Estado.

36 La evolución posterior de la cooperativa se estudia en (Caetano, Martí, y Moraes, 2016). 


\section{Referencias}

Abella, A. (1918). Utilidad de concentrar en manos de sociedades constituídas: industrialmente el comercio de la leche - Medios para fornentarlas. En R. O. U. Ministerio de Industrias (Ed.), Primer Congreso de la Leche (pp. 312-323). Montevideo: Imprenta Nacional.

Barela, L., Miguez, M., y García Conde, L. (2000). Algunos apuntes sobre historia oral. Buenos Aires: Instituto Histórico de la Ciudad de Buenos Aires.

Bertino, M., y Tajam, H. (2000). La agroindustria láctea en el Uruguay 1911-1943 Documento de Trabajo del Instituto de Economía (Vol. DT 4/00). Montevideo: Facultad de Ciencias Económicas y Administración - Universidad de la República.

Bértola, L. (1991). La Industria Manufacturera Uruguaya 1913-1961. Un enfoque sectorial de su crecimiento, fluctuaciones y crisis. Montevideo: CIEDUR- Facultad de Ciencias Sociales.

Birn, A.E., Cabella, W., y Pollero, R.. (2005). El estancamiento de la mortalidad infantil uruguaya en la primera mitad del siglo XX: Análisis por causas de enfermedad. En A. Asociación de Estudios de Población de la Argentina (Ed.), VII Jornadas Argentinas de Estudios de Población (pp. 137-154). Buenos Aires: Asociación de Estudios de Población de la Argentina.

Birn, A.E., Cabella, W., y Pollero, R.. (2010). The infant mortality conundrum in Uruguay during the first half of the twentieth century: an analysis according to causes of death. Continuity and Change, 25(03), 435-461.

Bisang, R., Novick, M., Sztulwark, S., y Yoguel, G. (2005). Las redes de producción y el empleo. Elementos básicos para la formulación de políticas públicas. En M. Casalet, M. Cimoli y G. Yoguel (Eds.), Redes, jerarquíasydinámicasproductivas. México, DF:FLACSO México-OIT-Miño y Dávila Editores.

Caetano, G., Martí, J.P., y Moraes, M.I. (2016). Conaprole, la historia. Montevideo: Eme Editorial.

Camilletti, A., Guidini, J., Herrera, A., Rodríguez, M., Martí, J.P., Soria, C., Torrelli, M., y Silveira, M. (2005). Cooperativas de trabajo en el Cono Sur. Matrices de surgimiento y modelos de gestión. Revista UniRcoop, 32-56.

Fenocchi, A.. (2000). Actualización del Libro de Andrés Fenocchi Fenocchi "La Capilla de Cardal". Recuperado de http://fenocchicapillacardal.webnode.com.uy/historia/, 11/06/2016. 
Ferrari Goudschaal, J. M.. (s.f). Evolución histórica del proceso de higienización y pasteurización de la leche de consumo para la ciudad de Montevideo - 1905 a 1935. Ponencia presentada en Sociedad Uruguaya de Historia de la Medicina V. XXVI.

Folguera, P.. (1994). Cómo se hace historia oral. Salamanca: EUDEMA.

Gide, Ch.. (1912). Économie sociale. Les institutions de progrès social (4è) Ed.). Paris: Librairie de la Société du Recueil Sirey.

Hjern, B., y Hull, C.. (1982). Implementation research as empirical constitutionalism. European journal of political research, 10(2), 105-115.

INALE, INSTITUTO NACIONAL DE LA LECHE. (2012). Informe semestral de situación y perspectivas de la lechería uruguaya. Período Enero-Junio 2012. http://www.inale.org/innovaportal/ file/1889/1/informe_de_coyuntura_primer_semestre_del_2012-_area_de_informacion_ inale.pdf

INE. (2010). Censo Nacional de Cooperativas y Sociedades de Fomento Rural (2008-2009). http:// www.ine.gub.uy/biblioteca/censoCoop_2008-2009/Censo-Nacional-de-Cooperativas.pdf

Jacob, R.. (1981). Uruguay, 1929-1938: Depresión ganadera y desarrollo fabril. Montevideo: Fundación de Cultura Universitaria.

Maeso, C. M. (1910). El Uruguay a través de un siglo. Montevideo: Tipográfica Moderna.

Martí, J.P.. (2013). La Cooperativa Nacional de Productores de Leche. Su creación analizada desde las políticas públicas. América Latina en la Historia Económica, Vol. 20, 90-113.

Martí, J.P.. (2014). La coopérative nationale de producteurs de lait de l'Uruguay: une régie coopérative? RECMA Revue Internationale de l'Économie Sociale, 331, 94-106.

Meny, Y., y Thoenig, J.C.. (1992). Las políticas públicas (F. Morata, Trans.): Ariel Barcelona.

Ministerio de Industrias, República Oriental del Uruguay. (1918). Primer Congreso de la Leche. Celebrado en Montevideo del 15 de febrero al 25 de marzo de 1918. Montevideo: Imprenta Nacional.

Nahum, B., Cocchi, A., Frega, A., y Trochón, Y.. (1988). Crisis política y recuperación económica, 19301958 (Vol. 7). Montevideo: Ed. Banda Oriental. 
Neffa, J.C.. (1986). La participación de los trabajadores en la gestión empresarial en la República del Perú (1968-1980). In I. I. d. E. Laborales (Ed.), Serie de investigación. Ginebra: OIT.

Olson, M.. (1978). Logique de l'action collective. Paris: Presses universitaires de France.

Piovani, Juan Ignacio. (2007). La entrevista en profundidad. En A. Marradi, N. Archenti y J. I. Piovani (Eds.), Metodología de las ciencias sociales (pp. 215-225). Buenos Aires, Argentina: emecé.

Sabatier, P. A. (1988). An advocacy coalition framework of policy change and the role of policy-oriented learning therein. Policy sciences, 21(2-3), 129-168.

Sabatier, Paul A. (1998). The advocacy coalition framework: revisions and relevance for Europe. Journal of European public policy, 5(1), 98-130.

Sabatier, P. A. (1986). Top-down and bottom-up approaches to implementation research: a critical analysis and suggested synthesis. Journal of public policy, 6(1), 21-48.

Sabatier, P. A., y Mazmanian, Daniel. (1979). The conditions of effective implementation: A guide to accomplishing policy objectives. Policy analysis, 5(4), 481-504.

Spear, R.. (2010). Co-operative Hybrids. Ponencia presentada en Co-operatives' contributions to a plural economy: Conference of Research Committee of the International Co-operative Alliance with the CRESS hone-Alpes and the University Lyon, Lyon, France. http://www. cress-rhone-alpes.org/cress/IMG/pdf/Spear_pap.pdf

Spear, R.. (2011). Formes coopératives hybrides. RECMA-Revue International de l'Économie Sociale, $320,26-42$.

Subirats, J., Knoepfel, P., Larrue, C., y Varone, F.. (2008). Análisis y gestión de políticas públicas (Vol. 1). Barcelona: Editorial Ariel.

Supervielle, M.. (1986). CONAPROLE Documento de trabajo. Montevideo: Instituto de Ciencias Sociales. Facultad de Derecho. Universidad de la República.

Tamayo Saenz, M. (1997). El análisis de las políticas públicas. En R. Bañón y E. Carrillo (Eds.), La nueva Administración Pública (pp. 281-312). Madrid: Alianza Universidad.

Terra, J.P.. (1986). Proceso y significado del cooperativismo uruguayo. Montevideo: Arca/CEPAL/ $\mathrm{EBO}$. 
Torrelli, M. (2012). El sector cooperativo y de la ESS visto a través de algunas de sus principales variables. Informe Uruguay. In OMERCOOPES (Ed.), Informes Nacionales y Regional de la Matriz de Datos cuantitativosy de política públicas. Montevideo: PROCOOPSUR, RECM-AECID.

Uruguay-XXI. (2012). Informe de comercio exterior de Uruguay. Año 2011. Recuperado de http://www.uruguayxxi.gub.uy/wp-content/uploads/2011/11/Informe-de-ComercioExterior-de-Uruguay-Diciembre-2011-Uruguay-XXI1.pdf

Uruguay_XXI. (2019a). Agronegocios. Oportunidades de inversión. Agosto 2019. Recuperado de https://www.uruguayxxi.gub.uy/uploads/informacion/c58a3bae82f4c5e3555cfe9c27ca746c7e04051e.pdf

Uruguay_XXI. (2019b). Exportaciones por empresas. from Uruguay XXI Recuperado de https://www. uruguayxxi.gub.uy/es/centro-informacion/articulo/exportaciones-por-empresas/

Valles, M. S. (2002). Entrevistas cualitativas (Vol. 32). Madrid: Centro de Investigaciones Sociológicas (CIS).

Vanek, J.. (1985). Imprese senza padrone nelle economie di mercato, a cura di B. Giuiliani. Roma: Edizioni Lavoro.

Varas, A.. (1997). Democratización y políticas públicas. En R. Urzúa (Ed.), Cambio Social y Políticas Públicas. Santiago de Chile: Centro de Análisis de Políticas Públicas - Universidad de Chile.

Vicens, B.. (1941). Régimen cooperativo. Montevideo: Palacio del Libro A. Monteverde y Cía.

Vuotto, M.. (2003). Charles Gide: una referencia singular para identificar la economía social y definir su identidad. En M. Vuotto (Ed.), Economía Social. Precisiones conceptuales y algunas experiencias históricas. Buenos Aires: Universidad Nacional de General Sarmiento-AltamiraFundación OSDE. 


\section{Anexos}

\section{Entrevistas realizadas}

\begin{tabular}{lcc}
\hline \multicolumn{1}{c}{ Entrevistado } & Entrevistador & Fecha \\
\hline $\begin{array}{l}\text { Pelayo Arocena Vásquez, hijo de Diego Arocena Capurro, } \\
\text { fundador de la Cooperativa de Lecherías S.A. }\end{array}$ & Juan Pablo Martí & 6 de junio de 2016 \\
\hline $\begin{array}{l}\text { Ruben Fenocchi, nieto de Andrés Fenocchi, fundador } \\
\text { de las Cooperativas de Lecherías S.A. }\end{array}$ & Juan Pablo Martí & 11 de junio de 2016 \\
\hline $\begin{array}{l}\text { José María Ferrari, médico e investigador especialista } \\
\text { en temas e higienización de la leche e hijo de Andrés }\end{array}$ & Juan Pablo Martí & 3 de junio de 2016 \\
\hline \begin{tabular}{l} 
Ferrari Vanoli, fundador de COLE S.A. y Conaprole \\
\hline
\end{tabular}
\end{tabular}

